\title{
The use of sewage treatment works as foraging sites by insectivorous bats
}

Kirsty J. Park and Andrew Cristinacce

Centre for Conservation Science, School of Biological and Environmental Sciences, University of Stirling, Stirling, Scotland, UK FK9 4LA

Address for Correspondence:

Kirsty Park,

Centre for Conservation Science,

School of Biological and Environmental Sciences,

University of Stirling, Stirling

Scotland, UK FK9 4LA

Tel. +44 (0) 1786467799

Fax +44 (0) 1786464994

Email: k.j.park@stir.ac.uk 


\section{ABSTRACT}

Sewage treatment works with percolating filter beds are known to provide profitable foraging areas for insectivorous birds due to their association with high macroinvertebrate densities. Fly larvae developing on filter beds at sewage treatment works may similarly provide a valuable resource for foraging bats. Over the last two decades, however, there has been a decline in filter beds towards a system of "activated sludge”. Insects and bat activity were surveyed at 30 sites in Scotland employing these two different types of sewage treatment in order to assess the possible implications of these changes for foraging bats. Bat activity (number of passes) recorded from broad-band bat detectors was quantified at three points within each site. The biomass of aerial insects, sampled over the same period as the detector surveys, was measured using a suction trap. The biomass of insects and activity of Pipistrellus spp. was significantly higher at filter beds than at activated sludge sites. In addition, whilst foraging activity of Pipistrellus spp. at filter beds was comparable to that of adjacent "good" foraging habitat, foraging at activated sludge sites was considerably lower. This study indicates the high potential value of an anthropogenic process to foraging bats, particularly in a landscape where their insect prey has undergone a marked decline, and suggests that the current preference for activated sludge systems is likely to reduce the value of treatment works as foraging sites for bats.

\section{INTRODUCTION}

\section{Sewage treatment works as wildlife habitats}

Urbanisation by expanding human populations can reduce native biological diversity by reducing the amount and quality of habitat available for wildlife, and by the fragmentation of remaining habitats (e.g. Marzluff, Gehlbach \& Manuwal 1998). In some instances, species vulnerable to habitat loss such as bats are able to exploit man-made structures and environments that may provide feeding opportunities and shelter. Some bat species now commonly use buildings as maternity 
roosts (Kunz \& Reynolds 2003), and exploit foraging opportunities provided by streetlamps that can attract large numbers of insects (Rydell 1992a).

Sewage treatment works have long been recognised as potentially valuable foraging areas for birds (e.g. Boyd 1957; Fuller \& Glue 1980) due to the availability of invertebrate prey. Sewage treatment works can encompass a diverse range of foraging habitats such as wetland areas and stabilisation ponds that can attract and support many wader, waterfowl and passerine species (e.g. Evans \& Harris 1994; Frederick \& McGehee 1994; Gough, Gillings \& Vickery 2003). At sites with percolating filter beds high densities of macroinvertebrates (e.g. oligochaete worms, crustacea and insects), that develop and/or live on the filter beds, provide food for many avian species, particularly pipits, wagtails, hirundines and starlings (Fuller \& Glue 1980; Fuller \& Glue 1981; Feare 1984; Gough et al. 2003). Another group of animals that may benefit from high densities of aerial insects are insectivorous bats, but whether bats use such sites, and how they may be affected by changes in operational practice is unknown.

\section{The status and conservation of bats in Europe}

There is evidence that many bat species in Europe have undergone large population declines during the $20^{\text {th }}$ Century (e.g. Stebbings 1988; Harris et al. 1995). One of the driving causes of these declines is believed to be the loss of roosting and foraging habitat (Stebbings 1988; Walsh, Harris \& Hutson 1995; Walsh \& Harris 1996a,b). In the UK all species of bats and their roosts are protected under UK (Wildlife and Countryside Act 1981 (as amended)) and international legislation, but foraging sites remain vulnerable to development and changes in land use (Hutson 1993). A UKwide bat survey in the 1990s found that habitats favoured by foraging bats were undergoing rapid rates of loss within the UK, and suggested that this may be limiting bats in some areas particularly within arable and pastural landscapes (Barr et al. 1993; Walsh et al. 1995). Declines in insect abundance over the last thirty years, associated with the intensification of agriculture, have been 
linked to declines in farmland bird populations (e.g. Benton et al. 2002), and have been suggested as a contributory factor in the decline of bat populations (Stebbings 1988; Gerell \& Lundberg 1993).

\section{Sewage treatment works: operational practice}

The two main types of secondary sewage treatment are percolating (or biological/trickling) filter beds and activated sludge (Gray 2005). At filter bed sites, after a screening and sedimentation process, waste water is sprayed over inert material and a microbial biomass, consisting of bacteria, fungi, protozoa and other mesofauna, develops as a film over the surface. This film supports a wide diversity of macroinvertebrates including dipteran fly larvae which feed upon it (Curds \& Hawkes 1975; Learner \& Chawner 1998; Gray 2005). In contrast, activated sludge treatment is a process in which a mixture of sewage and bacteria-laden sludge is agitated and aerated making it inhospitable for most aquatic species (Gray 2005). Activated sludge is now the dominant system for sewage treatment works serving populations of over 50,000 although filter beds are still commonly used for treating sewage from smaller populations (Gray 2005; Learner 2000).

The aim of this study was to investigate the use of sewage treatment works as foraging sites by bats, and specifically whether differences in their value to foraging bats exist between operational types. The following questions were addressed:

1. How does the abundance of nocturnal aerial insects differ between sewage work types?

2. Do the species of bat, and the levels of bat activity, differ between sewage work types?

3. What level of foraging resources do sewage works provide?

i. Do levels of bat activity at a sewage works simply reflect surrounding levels of activity? ii. How does bat activity inside the sewage works compare to activity in habitats considered important for foraging bats?

\section{METHODS AND MATERIALS}




\section{Study sites}

A total of 30 sewage treatment works (STW) were surveyed across central and southern Scotland between the $11^{\text {th }}$ June and the $21^{\text {st }}$ August 2003 (Table 1). Of these, 18 were filter bed and 12 were activated sludge treatment works and were under the operational control of Scottish Water. STW selection was based on the information provided by Scottish Water and such that any bias in size (population served), location (latitude, longitude and altitude) and surrounding habitat towards operational type was minimised (Table 1). The size of the STW ranged from 462 to 42,202 population served, and there was no significant difference between the two types (Mann-Whitney U test $\left.W_{18,12}=260, p=0.43\right)$.

Table 1

\section{Insect sampling}

A 9-inch diameter Johnson-Taylor insect suction trap (Johnson \& Taylor 1955) was used to assess the availability of aerial insects at each STW. The suction trap was positioned in a central location relative to the bat point counts. It was operated at the maximum speed $\left(850 \mathrm{~m}^{3} \mathrm{~h}^{-1}\right)$ from half an hour after dusk for two hours to cover the same time period as the bat surveys. Insects captured were identified to order or suborder level using Chinery (1993), and stored in 100\% ethanol. The number of insects captured during each two hour session was converted to density per $100 \mathrm{~m}^{3}$ of air. Once all samples had been collected and identified, the wet weight of insects was measured to the nearest $0.001 \mathrm{~g}$ to give biomass per sample.

The diets of the two Pipistrelle species that are widespread in the UK, $P$. pipistrellus and $P$. pygmaeus, consist largely of the dipteran suborder Nematocera (Barlow 1997). In order to assess long term changes in Nematocera abundance, a dataset of arthropods captured by a Rothamstedtype 12.2m high suction trap (Macaulay, Tatchell \& Taylor 1988) operating at Stirling University between 1972 and 1998 was examined. A paper describing long term changes in the abundance of 
insect orders from this dataset has been published (Benton et al. 2002). Previously unpublished data on Nematocera is presented in the current paper. The trend in Nematocera was identified using a generalised additive model, confidence intervals were generated using bootstrap resamples, and the trend was standardised by scaling it to start at 1.0. See Benton et al. 2002 for full description of the methods and analysis.

\section{Monitoring bat activity}

Point counts were used to assess bat activity. At each site 15 minute recordings were made at each of three locations within the STW. In addition, 2x15 minute recordings were made along river banks upstream from the sewage outlet, 50m and 75m outside the STW at 23 sites (15 filter bed, 8 activated sludge) as bat activity of Pipistrellus spp. may be reduced along rivers downstream of sewage outlets (Vaughan, Jones \& Harris 1996). At the remaining seven sites this was not possible. The median distance from the centre of each STW to the nearest river was $48.3 \mathrm{~m}$ (upper and lower interquartiles: 31.1, $84.3 \mathrm{~m}$ ). The first point count started $30 \mathrm{~min}$ after dusk and the last at $110 \mathrm{~min}$ after dusk. Between each 15 minute recording there was a gap of 5 minutes before the next recording was made. The first point count was randomly allocated to a STW or a riparian location adjacent to the works; once the location of this point had been determined, recordings alternated between STWs and riparian locations. At sites where it was not possible to conduct river point counts, an additional non-recording gap of 15 minutes was left before the next count. The three locations within each STW were a minimum of 25m apart and situated around the operational part of the works (i.e. filter beds and/or still-water sedimentation tanks). The bat detector was held at elbow height pointing towards the centre of the works. At river sites, the bat detector was directed towards the river. At the start and end of the recordings, air temperature was measured to the nearest $0.1^{\circ} \mathrm{C}$ and wind speed estimated using the Beaufort scale. The average of these readings was used for analytical purposes. Counts were only conducted in dry weather where the temperature at dusk exceeded $10^{\circ} \mathrm{C}$, and the strength of the wind did not exceed Beaufort 4 . 


\section{Sound recording and analysis}

A frequency division bat detector (Batbox Duet, Stag Electronics; frequency response 17-120kHz) was connected to a MiniDisc (Sony MZ-R909; frequency response $\pm 3 \mathrm{~dB} 20 \mathrm{~Hz}-20 \mathrm{kHz}$ ) and a continuous recording made at each point count onto a recordable MiniDisc. Frequency division is broad-band system that records all frequencies continuously, and is sufficient for distinguishing between the genera Myotis and Pipistrellus, and between the Pipistrellus species (e.g. Vaughan et al. 1996; see sound analysis). We analysed recordings using BatSound v3.31 (Pettersson Elektronik AB, Uppsala, Sweden), with a sampling frequency of $44.1 \mathrm{kHz}$ with 16 bits per sample, and a 512 pt. FFT with Hanning window). One bat pass was defined as a continuous sequence of at least two echolocation calls from a passing bat (Fenton 1970, Walsh et al. 1996a).

Three genera of bat occur in the area where this study was conducted; Pipistrellus, Myotis and Plecotus (Richardson 2000), although Plecotus is rarely recorded due to its quiet echolocation calls. Calls of Myotis and Pipistrellus species can be distinguished by differences in call structure. The calls of the two Myotis spp. found in the study area, $M$. daubentonii and M. nattereri, are difficult to distinguish, and no further classification was made for this group. The three Pipistrellus species present in the UK can be distinguished on the basis of the peak frequency of their search-phase echolocation calls (FMAXE): bat passes with a mean FMAXE of $40-49 \mathrm{kHz}$, of greater than $52 \mathrm{kHz}$, and of less than $40 \mathrm{kHz}$ were classified as $P$. pipistrellus, $P$. pygmaeus, and $P$. nathusii respectively (Jones \& van Parijs 1993; Vaughan, Jones \& Harris 1997a). Bat passes with an FMAXE between 49 and $52 \mathrm{kHz}$, or with calls unsuitable for analysis, were classed as unknown Pipistrellus sp. Terminal feeding buzzes emitted when attempting prey capture (Griffin, Webster \& Michael 1960) were also counted, and feeding rate was expressed both as the number of feeding buzzes and the buzz ratio, the ratio of feeding buzzes to bat passes which provides a measure of foraging effort per unit of flight activity (Vaughan et al. 1996; Wickramasinghe et al. 2003). Sound analysis was carried out blind to the site being analysed. 


\section{Habitat availability}

Of the 30 STW surveyed, the majority (28) were in $1 \mathrm{~km}$ squares classed as arable or pastural land, one as marginal upland and one as urban (Countryside Information System v7.02). An Ordnance Survey Land-Form.Plus multiscale model (DTM) ( Crown Copyright Ordnance Survey. An EDINA Digimap/JISC supplied service) was obtained for the study sites, allowing topographical features such as vegetation type, rivers, buildings etc to be generated in a Geographic Information System (ArcView GIS v3.2, ESRI). For most sites, a scale of 1:2500 was used, but for some STW near larger conurbations $(n=7)$, the scale was $1: 1250$. The proportion of different habitats within a $50 \mathrm{~m}$ radius of the suction trap position, and a 500m radius from the centre of the STW was calculated. Habitat around the suction trap was categorised as: grassland; water (e.g. rivers); concrete (e.g. roads, paving); woodland, and filter beds (or open still-water tanks at activated sludge sites). Habitat around the STW was categorised as woodland, agricultural, water, and built-up land. Although 50m and 500m are arbitrary figures they provide a broad picture of the habitat immediately at, and around, each site enabling any bias in habitat at, and surrounding, the two types of STW to be identified.

\section{Data analysis}

Since the proportion of Pipistrellus spp. passes classified as $P$. pipistrellus was very low (Table 2), we have assumed that the majority of unidentified Pipistrellus sp. passes are also P. pygmaeus, and for analysis purposes all passes classified as Pipistrellus spp. were used. Bat activity was quantified as the total number of Pipistrellus spp. and Myotis spp. passes at each site, or for comparative analyses with riparian sites outside the STW, the mean number of passes. Although numbers of bat passes counted over a specified length of transect or time period does not allow the number of bats using that site to be quantified, it does provide a measure of activity at that site, enabling comparisons between sites (Fenton 1970). 
Data were transformed, where necessary, to achieve normality and homoscedasticity, or non parametric tests were adopted. The approach used for general linear models (GLM) was the inclusion of a number of explanatory variables with their interactions (two way interactions were the maximum used) in a starting model followed by model simplification through stepwise elimination of non-significant explanatory variables. MANOVAs were used to investigate differences in habitat between sewage treatment type. Statistical analyses were carried out using Minitab release 13.1 (Ryan \& Joiner 1994) and Genstat 5 release 4.1 (IACR - Rothamsted) with a significance level of 5\%. All statistical tests conducted were two-tailed, and errors are expressed as standard errors (SE) of the mean unless otherwise stated.

\section{RESULTS}

\section{Insect availability}

Almost all the insects captured in the suction trap were in the dipteran suborder Nematocera, with a median percentage of $99.9 \%$ and $100 \%$ at filter bed and activated sludge sites respectively. The other two suborders of Diptera (Brachycera and Cyclorrhapha), and seven other orders (Trichoptera, Coleoptera, Hemiptera, Thysanoptera, Lepidoptera, Hymenoptera and Psocoptera) were represented by very small numbers ( $<5$ individuals per site at a small number of sites), with the exception of one site where Caddis flies (Trichoptera: Caddis flies) comprised $16.4 \%$ of the total number caught. On average, grass (mostly short mown grass, plus a small proportion of long grass) accounted for the highest proportion of habitat within a 50m radius of the suction trap at each site. There were no significant differences in the habitat surrounding the suction trap between the two sewage treatment types from either multivariate tests (Wilks $\lambda=0.731, F_{5,24}=1.764, p=0.16$ ) or univariate tests of each habitat category.

Biomass and total density of insects were significantly correlated (Pearson correlation coefficient $\left.r_{30}=0.49, p=0.006\right)$. A GLM was constructed with insect biomass as the dependent variable, and 
STW type (factor), temperature, size, wind and date (covariates) as explanatory variables. All two way interactions between explanatory variables were included, excluding those with date. The final model consisted only of STW type and temperature. The biomass of insects at filter bed sites was significantly greater than at activated sludge sites $\left(F_{1,27}=14.85, p=0.001 ; \beta=0.026, \mathrm{SE}=0.007\right.$ (filter bed sites); Fig. 1$)$, and was positively correlated with temperature $\left(F_{1,27}=4.83, p=0.037 ; \beta=\right.$ 0.006, SE $=0.003)$. STW type and temperature explained $32.3 \%$ of the variation observed in insect biomass between sites. Using density of insects (ln transformed) as a measure of insect availability gave similar results, with higher numbers of insects at percolating filter beds than activated sludge sites $\left(F_{1,25}=9.68, p=0.005 ; \beta=0.552, \mathrm{SE}=0.177\right.$ (filter bed sites)).

Fig. 1

\section{Long term changes in Nematocera abundance}

Numbers of Nematocera counted from the Stirling University suction trap have declined over the period 1972 to 1998 (Fig. 2). This decline has not been linear and periods of decline (e.g. mid 1970s, mid 1990s) have been interspersed with periods of high abundance (e.g. early 1980s). The abundance in 1998 (as a fraction of 1972) was 0.47 (using mean counts per year).

Fig. 2

\section{Bat activity}

Bats were recorded at 27 of 30 STW surveyed; P. pygmaeus at 24 STW, $P$. pipistrellus at 19 STW and Myotis spp. at ten STW. In addition, at three sites, passes with a mean FMAXE of less than 40 kHz were recorded, indicating $P$. nathusii. A total of 5644 bat passes were recorded during 34 hours of recordings. Of these, approximately 70\% were classified as Pipistrellus spp., 6\% as Myotis spp. and $24 \%$ as unknown bat passes (Table 2). For sites where the total number of bat passes exceeded ten, there was no significiant in the proportion of passes classified as unknown between STW type 
$\left(F_{1,20}=0.52, p=0.478\right) . P$. pygmaeus made up the vast majority of the identified Pipistrellus passes: of those passes classified to species, 95\% were $P$. pygmaeus.

Table 2

Habitat availability around sewage works

Within a 500m radius of each STW, “agricultural” land including arable, pasture, amenity grass and areas with a mixture of open grassland and low scrub accounted for the greatest proportion of habitat, with built-up land and woodland accounting for the next most common habitats and water (rivers, ponds etc) the least. There were no significant differences in the habitat surrounding each site between the two sewage treatment types (Wilks $\lambda=0.731, F_{5,24}=1.767, p=0.158$ ), although univariate tests of each habitat category did indicate that there was a significantly higher proportion of built-up land surrounding activated sludge sites than filter bed sites $\left(F_{1,28}=6.27, p=0.018\right.$; $\beta=$ 4.526, SE $=1.808)$.

\section{Comparison between treatment types}

A GLM was constructed with total Pipistrellus spp. activity (ln transformed) as the dependent variable, STW type as a factor, and temperature, size, wind and date as continuous variables (covariates). All two way interactions between explanatory variables were included, excluding those with date. Since the proportion of "built-up" land was shown to differ between the two types of STW in the univariate tests of habitat, the variable was transformed using an arcsine square-root and included as a covariate, and in a two way interaction with STW type.

Pipistrellus spp. activity at filter beds was significantly higher than at activated sludge sites (Table

3, Fig. 3). Temperature and proportion of built-up land correlated positively, and date negatively, with activity, and the final model explained $57.9 \%$ of the variation in activity between sites. The parameter estimates and associated significance values for the interaction between wind and type 
indicated no relationship between Pipistrellus spp. activity and wind strength at percolating filter bed sites $(\beta=0.36, p=0.083)$, but a significant negative relationship between Pipistrellus spp. activity and wind strength at activated sludge sites $(\beta=-1.201, p<0.001)$. There was no significant difference between wind strength at the two STW types $\left(t_{18,12}=-1.5, p=0.15\right)$.

Table 3

Fig. 3

Myotis spp. were detected at 6/18 percolating filter bed sites and 4/12 activated sludge sites. Due to the large number of sites where no Myotis spp. were detected, there were insufficient data to analyse Myotis spp. activity in a similar way to Pipistrellus spp. activity.

\section{Foraging at STW versus adjacent riparian sites}

In order to assess whether bat activity at STW simply reflected activity levels in surrounding riparian areas, a GLM was constructed using mean Pipistrellus spp. activity (ln transformed) within each STW as the response variable, with mean Pipistrellus spp. activity (ln transformed) outside the STW adjacent to a river (covariate), type of STW (factor), and an interaction term as explanatory variables. Mean Pipistrellus spp. activity within STW was positively correlated with Pipistrellus spp. activity outside the STW $\left(F_{1,20}=6.45, p=0.02 ; \beta=0.397, \mathrm{SE}=0.156\right)$ but STW type remained significant $\left(F_{1,20}=6.71, p=0.017 ; \beta=0.643, \mathrm{SE}=0.248\right.$ (filter bed sites)), with more Pipistrellus spp. activity at filter bed sites than activated sludge sites. The interaction term was not significant and was removed from the final model, which explained 34.9\% of the variation in activity between STW sites. There was no significant difference between the mean number of passes at filter bed sites and paired riparian locations $\left(t_{15}=-1.13, p=0.28\right.$, Fig. 4$)$. In contrast, there was a significantly lower number of passes within activated sludge sites in comparison to paired riparian locations ( $t_{8}=-2.84, p=0.025$, Fig. 4). 
Fig. 4

There was significantly more Myotis spp. activity at riparian locations outside filter bed sites compared with activity within the STW (Wilcoxon matched pair $W_{11}=65.0, p=0.005$ ). Once zeros had been excluded, there were insufficient data to test for a difference at activated sludge sites.

\section{Feeding buzzes}

On average, $7.5 \%$ of passes had feeding buzzes, ranging between zero and $16.7 \%$ per point count, for points with more than 10 passes. There was a significant positive correlation between the number of feeding buzzes and insect biomass at STW (Spearman rank $r_{\mathrm{s} 30}=0.43, \mathrm{p}=0.019$ ). Whilst there was no significant difference in the number of feeding buzzes between the paired sites for filter bed sites $\left(t_{15}=-1.39, p=0.185\right)$, there were significantly fewer feeding buzzes within activated sludge sites than at riparian locations adjacent to them $\left(t_{8}=2.56, p=0.038\right)$. Similarly, there was no significant difference in the buzz ratios between the paired sites for filter bed sites (Wilcoxon statistic $=52.0, p=1.0, \mathrm{n}=15$ ), but there was a significantly lower buzz ratio at activated sludge sites in comparison with paired riparian sites (Wilcoxon statistic $=21.0, p=0.036$, $\mathrm{n}=8)$.

\section{DISCUSSION}

Results from this study show that bats commonly feed at sewage treatment works, but that the type of secondary treatment employed at these sites influences the biomass and number of nocturnal aerial insects and consequently the value of the site to foraging bats, in particular $P$. pygmaeus. Levels of activity at filter bed sites were considerably higher than those at activated sludge sites, and whilst activity over filter beds was comparable to nearby riparian sites, activity at activated sludge sites was significantly lower. Three specific questions regarding insect and bat activity at 
sewage treatment works were outlined in the introduction to this study, and these are addressed below.

\section{How does the abundance of nocturnal aerial insects differ between sewage work types?}

In this study the biomass of nocturnal aerial insects sampled by a suction trap at sewage treatment works that used activated sludge as a secondary treatment was only $42 \%$ of the biomass of insects at percolating filter sites. With the exception of Thysanoptera (Thrips), all the orders represented in the suction trap samples have been found in dietary analyses of Pipistrellus spp. and Myotis spp. (reviewed in Vaughan 1997), indicating that these samples are a useful measure of the availability of insects to the bats detected at the STW. The majority of insects captured belonged to the dipteran suborder Nematocera which is the main insect prey group for both $P$. pygmaeus and $P$. pipistrellus (Barlow 1997).

\section{Do the species of bat, and the levels of bat activity, differ between sewage work types?}

Bats were detected at $90 \%$ of STW visited and feeding buzzes were recorded at $67 \%$ of sites where bats were detected, confirming that bats were actively foraging at sewage treatment works. A higher number of bat passes were classified as unidentified bat or unidentified Pipistrellus than has been documented in similar studies (e.g. Vaughan et al. 1996). Many of these calls were quite faint and the background noise of the sewage treatment works sometimes made classification problematic. Nevertheless, the proportions of calls assigned to genera or species was comparable to proportions of population estimates in Scotland (although these population estimates had a low level of confidence attached; Harris et al. 1995), and the dominance of P. pygmaeus as the more common Pipistrellus species in Scotland has been noted previously (Jones \& van Parijs 1993). The level of activity between the two types of treatment works differed substantially: the total number of Pipistrellus spp. passes recorded at activated sludge sites was 57\% of those recorded at percolating filter sites. Since P. pygmaeus use buildings extensively as maternity sites in summer (e.g. 
Altringham 2003), it is possible that the positive association between built-up land and number of passes reflects a higher number of roosts within the vicinity of STW with a larger proportion of built-up land nearby. Wind was negatively correlated with activity at activated sludge sites but had little effect at filter bed sites. Since there was no significant difference in the strength of wind recorded at the two treatment types, it is possible that this finding is due to the reduced availability of insects at activated sludge sites given that wind should disperse lower densities of insects more readily than it does high densities.

\section{What level of foraging resources do sewage works provide?}

Do levels of Pipistrellus spp. activity at sewage works simply reflect surrounding levels of activity?

Overall, there was no significant difference in the habitat surrounding the two types of STW, although the proportion of built-up land was higher around activated sludge sites than filter beds. The inclusion of this variable in the model of Pipistrellus spp. activity did not affect the significance of STW type as an explanatory variable for activity. Secondly, although there was a significant positive correlation between Pipistrellus spp. activity within and outside the STW, the type of treatment works remained significant. This indicates that the difference in Pipistrellus spp. activity found between filter bed and activated sludge sites is not an artefact of differences in surrounding habitat or bat populations, and that higher activity at filter bed sites is due to the presence of the filter beds on which insects develop.

How does bat activity inside sewage works compare to activity in habitats considered important for foraging bats?

In general, freshwater habitats are considered good foraging areas for bats due to high insect densities, and high levels of Pipistrellus spp. activity have repeatedly been recorded over rivers, lakes and other riparian habitats (e.g. Swift \& Racey 1983; Racey \& Swift 1985; Walsh \& Harris 
1996a; Vaughan, Jones \& Harris 1997b). Of the two commonly recorded species of Pipistrellus in the $\mathrm{UK}$, the $55 \mathrm{kHz}$ phonic type (now $P$. pygmaeus) is particularly associated with riparian habitats and this is reflected in their diet (Barlow 1997; Vaughan et al. 1997b). Data from the present study indicate that whilst activity within filter bed sites compares favourably to riparian habitat outside the STW (87\% of levels at paired riparian sites), activity within activated sludge sites was considerably lower than adjacent riparian sites ( $46 \%$ of levels at paired riparian sites). In addition, both the number of feeding buzzes, and the foraging effort per echolocation call (buzz ratio), were significantly higher at riparian locations outside activated sludge sites. In contrast, there was no difference between feeding activity at filter bed sites and adjacent riparian locations. Although analyses of Myotis spp. passes were limited, they do indicate a different pattern to P. pygmaeus, in that activity levels were significantly lower within filter bed sites than at adjacent riparian sites. Of all the species likely to have been recorded in this study, the association between water and $M$. daubentonii is particularly marked as this species feeds largely on insect prey from the water surface or just above it (Jones \& Rayner 1988).

\section{Conclusions}

In this study the number of feeding buzzes correlated positively with insect biomass across 30 sites (see also Racey \& Swift 1985). This suggests that areas with high insect densities represent good quality foraging sites. In addition, bats may remain loyal to specific foraging areas (e.g. Brigham \& Fenton 1986; Altringham 2003). Consequently, changes in foraging habitats that reduce insect densities might be expected to impact negatively on bat populations (Gerell \& Lundberg 1993; Vaughan et al. 1996). The identification and maintenance of high quality foraging sites is therefore important for bat conservation.

Although it remains the most abundant and widespread bat species in the UK, estimates from the Annual Bat Colony Survey in the UK suggest a decline of over 60\% between 1978 and 1993 for 
Pipistrellus spp. (Hutson 1993). Since the two phonic types have only recently been separated, it is not possible to assign an estimate of decline to the two species separately. There is also evidence that the abundance of Pipistrellus spp. is lower in Scotland as it is nearer the northern edge of its distributional range (Walsh \& Harris 1996b). Because of a restricted annual reproductive rate, bats can be slow to recover from population declines and small population sizes make them particularly susceptible to further perturbations (Harris et al. 1995; Racey \& Entwistle 2000).

Habitats identified as being the most favourable to bats have suffered large reductions during the past century, in part due to the expansion and intensification of farming (Walsh \& Harris 1996a; Wickramasinghe et al. 2003). In this study we found that numbers of Nematocera, the main prey group of $P$. pygmaeus, have followed the declines noted for some other arthropod species which appear to be associated with changes in agricultural practices over the last thirty years (Benton et al. 2002). Benton et al. (2002) suggest that trends identified from the suction trap at Stirling University are representative of a considerable geographical area. Given that the mean distance of Stirling University to the STW visited in this study is only $29.4 \pm 3.2 \mathrm{~km}$ it is likely that trends observed from changes in Nematocera numbers at this suction trap are reflected over the wider geographical area covered by these sites. In the current study insect biomass and bat activity was only surveyed over a three month period (June-August). Studies of adult fly activity at filter bed sites, however, show peak numbers for some species occurring in spring, whereas in other species peak numbers are found during summer or autumn (Learner 2000). This suggests that filter beds may provide a foraging resource for bats throughout the active season, and possibly even during arousal episodes from hibernation as flies can be captured above filter beds throughout winter, albeit in lower numbers (Learner 2000). Such benefits, however, appear to differ between bat species presumably because of differences in foraging style and diet. In Scotland, bat diversity is low and this study relates largely to $P$. pygmaeus. In other parts of the UK, where species diversity is greater, patterns of foraging at sewage treatment works may differ. Other than species in the Pipistrellus genus, 
other European bat species which feed on large numbers of nematoceran Diptera (but do not forage predominately low over water surfaces) and may therefore forage at sewage treatment works include Rhinolophus hipposideros, Myotis brandtii, M. mystacinus, M. nattereri, Nyctalus leisleri, N. noctula (reviewed in Vaughan 1997), Eptesicus nilssoni (Gajdosik \& Gaisler 2004), and Vespertilio murinus (Rydell 1992b).

Some animals are particularly adept at exploiting opportunities created by man-made structures, not intentionally designed for them. For species whose populations are limited by a lack of fundamental resources, such as resting (or roosting/nesting) and foraging sites, such structures can represent good conservation value (e.g. buildings with suitable cavities for the endangered Lesser Kestrel Falco naumanni, Franco, Marques \& Sutherland 2005). This is increasingly being recognised and in some quarters there is encouragement for buildings to incorporate more wildlife-friendly features (e.g. Greater London Authority 2002). Species able to capitalise on such features, however, remain vulnerable to human whim and technological changes. Many bat species roost in artificial structures but may be excluded when, for example, mines are sealed to prevent human access or roosts in buildings are evicted because of human disturbance or persecution (Racey \& Entwhistle 2000). Rydell (1992a) suggested that by attracting insects, mercury streetlamps provide local patches of food for some bat species and could be important during periods critical for their survival and reproduction. The increased use of more energy-efficient low pressure sodium lamps, which do not attract insects, in the 1990s may therefore have reduced the value of street lighting to these bats (Rydell 1992a; Rydell \& Racey 1995). Results from the current study indicate that other man-made structures or anthropogenic processes such as the treatment of sewage using percolating filter beds can provide a valuable foraging resource for bats due to the emergence of aquatic insects whose larvae develop on the beds. Fuller \& Glue (1981) suggested that the development of percolating filter beds had created an entirely new avian niche, with their surface macrofauna providing food for highly characteristic assemblages of birds throughout the year. A comparison between the 
prevalence of bird species at sewage treatment works and in the wider countryside indicated the importance of such sites for particular species including the grey wagtail, starling and house martin, all species on the amber list of the Birds of Conservation Concern in the UK (Gough et al. 2003).

When Fuller \& Glue conducted their survey of STWs (1980) percolating filter beds were the most commonly used method of secondary sewage treatment. In 1972 it was estimated that about $50 \%$ of sewage given biological oxidation treatment in England \& Wales went through filter bed sites, although many more of the 5000 or so STWs employed filter bed rather than activated sludge technology (Institute of Water Pollution Control 1972). Since 1970, however, the majority of new domestic and municipal STW plants built have been of the activated sludge type (Gray 2005). Data on sewage treatment type within the area formerly covered by East and West of Scotland Water (now Scottish Water), indicate that percolating filter beds are now only used as a secondary treatment for approximately $9 \%$ of the population, but represent $55 \%$ of the number of sites (total $\mathrm{n}=213$ ). Filter beds are still commonly used for treating sewage from smaller populations elsewhere in Europe and are common in other temperate regions (Learner \& Chawner 1998). The reasons for the changes in operating practice were in part due to the smaller area of land required for activated sludge systems and the fly nuisance associated with filter beds (Gray 2005; N. F. Gray pers comm.). The benefits of percolating filter bed systems include lower operational costs and energy requirements, reduced noise, technical skill and maintenance requirements (Learner \& Chawner 1998; Gray 2005). In addition, when filter beds are managed effectively, the effluent quality is higher and more reliable than activated sludge systems (N. F. Gray pers. comm.). Percolating filter beds also provide benefits to wildlife by providing a foraging resource, and this study has highlighted their use by insectivorous bats.

Although filter beds cover relatively small areas, they are numerous and distributed widely throughout the countryside (Gray 2005). Most sewage treatment works are situated close to 
buildings that may act as maternity roosts, particularly for Pipistrellus spp., and could represent important local foraging patches for pregnant and lactating females, at a time of year when energetic requirements are especially high. This may be especially important given that sewage works are generally situated within an agricultural landscape that has seen large declines in insect numbers over the last 30 years. The current preference for activated sludge systems is likely to be detrimental to the value of treatment works as foraging sites for insectivorous animals. It is possible, however, that sympathetic habitat management at these sites may help reduce the negative impact of such conversions. Habitat management recommendations for birds arising from a recent survey of treatment works by the British Trust for Ornithology include the creation and maintenance of woodland and wetland habitats (Gough et al. 2003), and these are also likely to be beneficial to foraging bats.

\section{ACKNOWLEDGEMENTS}

Many thanks to Kate Buchanan and Nancy Jennings for useful discussions and comments on the manuscript, Catriona Stephenson for help with GIS, David Howard for the land class data, and Tim Benton for the loan of equipment and the data analysis from the Stirling University suction trap. The manuscript was improved by comments from two anonymous referees and the Editor. We are very grateful to Scottish Water, in particular Derek Somers and all the site workers for advice and access to the sites. KJP was funded by a Special Research Fellowship (Leverhulme), the Scottish Higher Education Funding Council, The Royal Society, The Lindeth Trust, and The British Ecological Society. 


\section{REFERENCES}

Altringham, J. D. (2003). British Bats. The New Naturalist. Harper Collins, London, UK.

Barlow, K. E. (1997). The diets of two phonic types of the Pipistrellus pipistrellus in Britain. J. Zool. Lond. 243: 597-609.

Barr, C. J., Bunce, R. G. H., Clarke, R. T., Fuller R. M., Furse, M. T., Gillespie, M. K., Groom, G. B., Hallam, C. J., Hornung, M., Howard, D. C. \& Ness, M. J. (1993). Countryside Survey 1990 - main report. London: Department of the Environment.

Benton, T. G., Bryant, D. M., Cole, L. \& Crick, H. Q. P. (2002). Linking agricultural practice to insect and bird populations: a historical study over three decades. J. Appl. Ecol. 39, 673-687.

Boyd, A. W. (1957). Sewage farms as bird habitats. British Birds 50, 253-263.

Brigham, R. M. \& Fenton, M. B. (1986). The influence of roost closure on the roosting and foraging behaviour of Eptesicus fuscus (Chiroptera: Vespertilionidae). Can. J. Zool. 64, 1128-1133.

Chinery, M. (1993). Collins guide to the insects of Britain and Western Europe. London: Collins.

Curds, C. R. \& Hawkes, H. A. (1975). Ecological aspects of used-water treatment. Vol. I. The organisms and their ecology. London: Academic Press.

Evans, T. J. \& Harris, S. W. (1994). Status and habitat use by American Avocets wintering at Humboldt bay, California. The Condor 96, 178-189.

Feare, C. (1984). The Starling. Oxford: Oxford University Press.

Fenton, M. B. (1970). A technique for monitoring bat activity with results obtained from different environments in southern Ontario. Can. J. Zool. 48, 847-851.

Franco, A.M.A., Marques J.T. \& Sutherland W.J. 2005. Is nest-site availability limiting Lesser Kestrel populations. A mutliple scale approach. Ibis 147, 657-666.

Frederick, P. C. \& McGehee, S. M. (1994). Wading bird use of wastewater treatment wetlands in Central Florida, USA. Colonial Waterbirds 17, 50-59.

Fuller, R. J. \& Glue, D. E. (1980). Sewage works as bird habitats in Britain. Biol. Cons. 17, 165181.

Fuller R. J. \& Glue, D. E. (1981). The impact on bird communities of the modernisation of sewage treatment works. Effluent Water Treat.21, 27-31.

Gajdoski M. \& Gaisler J. (2004). Diet of two Eptesicus bat species in Moravia (Czech Republic). Folia Zool. 52, 7-16.

Gerell, R. \& Gerell-Lundberg, K. (1993). Decline of a bat Pipistrellus pipistrellus population in an industrialised area in South Sweden. Biol. Cons. 65, 153-157.

Gough, S. J., Gillings, S. \& Vickery, J. A. (2003). The value and management of wastewater treatment works for breeding and wintering birds in lowland eastern England. BTO Research Report No. 333. Norfolk: British Trust for Ornithology.

Gray, N. F. (2005) Water Technology: an introduction for environmental scientists and engineers. $2^{\text {nd }}$ edition. Oxford: Elsevier Butterworth-Heinemann.

Greater London Authority 2002. Connecting with London's nature: The Mayor's Biodiversity Strategy. London: GLA.

Griffin, D. R., Webster, F. A. \& Michael, C. R. (1960). The echolocation of flying insects by bats. Anim. Behav. 8, 141-154.

Harris, S., Morris, P., Wray, S. \& Yalden, D. (1995). A review of British mammals: population estimates and conservation status of British mammals other than cetaceans. Peterborough: Joint Nature Conservation Committee.

Hutson, A. M. (1993). Action Plan for the Conservation of Bats in the United Kingdom. London: Bat Conservation Trust.

Institute of Water Pollution Control. 1972. Maidstone: IWPC.

Johnson, C. G. \& Taylor, L. R. (1955). The development of large suction traps for airborne insects. Ann. Appl. Biol. 43, 51-61.

Jones, G. \& Rayner, J. M. V. (1988). Flight performance, foraging tactics and echolocation in freeliving Daubenton’s bats (Myotis daubentonii (Chiroptera: Vespertilionidae)). J. Zool. Lond. 215, 113-132. 
Jones, G. \& van Parijs, S. M. (1993). Bimodal echolocation in pipistrelle bats - are cryptic species present? P. Roy. Soc. Lond. B 251, 119-125

Kunz, T. H. \& Reynolds, D. S. (2003). Bat colonies in buildings. In: Monitoring trends in bat populations of the US and Territories: problems and prospects (T. J. O’Shea \& M. A. Bogan, eds.). Washington DC: US Geological Survey, Biological Resources Discipline, Information and Technology Report.

Learner, M. A. (2000). Egression of flies from sewage filter-beds. Water Res. 34, 877-889.

Learner, M. A. \& Chawner, H. A. (1998). Macro-invertebrate associations in sewage filter-beds and their relationship to operational practice. J. Appl. Ecol. 35, 720-747.

Macaulay, E. D. M. Tatchell, G. M. \& Taylor, L. R. (1988). The Rothamsted Insect Survey '12 metre' suction trap. B. Entomol. Res. 78, 121-129.

Marzluff, J. M., Gehlbach, F. R. \& Manuwal, D. A. (1998). Urban environments: influences on avifauna and challenges for the avian conservationist. In: Avian Conservation (Marzluff JM, Sallabanks eds), pp 283-305. Washington DC: Island Press.

Racey, P. A. \& Entwistle, A. C. (2000). Life-history and reproductive strategies of bats. In: Reproductive Biology of Bats (Crichton EG, Krutzsch PH eds), pp 363-414. London: Academic Press.

Racey, P. A. \& Swift, S. M. (1985). Feeding ecology of Pipistrellus pipistrellus (Chiroptera: Vespertilionidae) during pregnancy and lactation. I. Foraging behaviour. J. Anim. Ecol. 54, 205-215.

Richardson, P. (2000). Distribution atlas of bats in Britain and Ireland 1980-1999. London: Bat Conservation Trust.

Ryan, B. F. \& Joiner, B. L. (1994). Minitab handbook. $3^{\text {rd }}$ edition. Belmont, CA: Duxbury Press.

Rydell, J. (1992a). Exploitation of insects around streetlamps by bats in Sweden. Func. Ecol. 6, 744-750.

Rydell, J. (1992b). The diet of the parti-coloured bat Vespertilio murinus in Sweden. Ecography 15, 195-198.

Rydell, J. \& Racey, P.A. (1995). Street lamps and the feeding ecology of insectivorous bats. Symp. Zool. Soc. Lond. 67, 291-307.

Stebbings, R. E. (1988). Conservation of European bats. London: Christopher Helm.

Swift, S. M. \& Racey, P. A. (1983). Resource partitioning in two species of vespertilionid bats (Chiroptera) occupying the same roost. J. Zool. Lond. 200, 249-259.

Vaughan, N. (1997). The diets of British bats (Chiroptera). Mamm. Rev. 27, 77-94.

Vaughan, N., Jones, G. \& Harris, S. (1996). Effects of sewage effluent on the activity of bats (Chiroptera: Vespertilionidae) foraging along rivers. Biol. Cons. 78, 337-343.

Vaughan, N., Jones, G. \& Harris, S. (1997a). Identification of British bat species by multivariate analysis of echolocation call parameters. Bioacoustics 7, 189-207.

Vaughan, N., Jones, G. \& Harris, S. (1997b). Habitat use by bats (Chiroptera) assessed by means of a broad-band acoustic method. J. Appl. Ecol. 34, 716-730.

Walsh, A. \& Harris, S. (1996a). Foraging habitat preferences of vespertilionid bats in Britain. J. Appl. Ecol. 33, 508-518.

Walsh, A. \& Harris, S. (1996b). Factors determining the abundance of vespertilionid bats in Britain: geographical, land class and local habitat relationships. J. Appl. Ecol. 33, 519-529.

Walsh, A., Harris, S. \& Hutson, A. M. (1995). Abundance and habitat selection of foraging vespertilionid bats in Britain: a landscape-scale approach. Symp. Zool. Soc. Lond. 67, 325344.

Wickramasinghe, L. P., Harris, S., Jones, G. \& Vaughan, N. (2003). Bat activity and species richness on organic and conventional farms: impacts of agricultural intensification. J. Appl. Ecol. 40, 984-993. 


\section{Table and Figure legends}

Table 1

Locations and attributes of sewage treatment work sites visited. AS = activated sludge sites, $\mathrm{PF}=$ percolating filter bed sites.

Table 2

Classification of bat passes recorded at sewage treatment works.

Footnote for Table 2:

Although five passes with an average FMAXE $<40 \mathrm{kHz}$ were recorded at three sites, further surveying is required before the presence of Pipistrellus nathusii can be confirmed at these sites.

Table 3

GLM for the effects of sewage treatment work type on log transformed numbers of Pipistrellus spp. passes. Temperature, date, wind strength, proportion of built up land within $500 \mathrm{~m}$ of the site (transformed using arcsine sqrt), and an interaction term between treatment type and wind strength were included as covariates. For factor "STW type" the parameter coefficient and associated standard error is for filter bed sites.

Fig. 1

Adjusted mean biomass (g) of insects collected during 2-hour suction trap sessions at filter bed sites $(n=18)$, and activated sludge sites $(n=12)$. Error bars are standard errors of the mean.

Fig. 2

Trend in the number of Nematocera flies caught over 27 years by a suction trap at Stirling University. The trend is the partial fits for year within a GAM. A 12d.f. spline was chosen as the best model of the trend. The partial fits are standardised so year 1=1. Data supplied by T.G. Benton. See Benton et al. 2002 for further details.

Fig. 3

Adjusted total number of Pipistrellus spp. passes at filter bed sites $(\mathrm{n}=18)$, and activated sludge sites $(n=12)$. Error bars are standard errors of the mean.

Fig. 4

Adjusted mean number of Pipistrellus spp. passes at paired sewage treatment work (STW, $n=3$ per site) and adjacent riparian sites ( $\mathrm{n}=2$ per site). Filter bed sites $=13$, activated sludge sites $=8$. Error bars are standard errors of the mean. 
Table 1

\begin{tabular}{|c|c|c|c|c|c|}
\hline Site name & $\begin{array}{l}\text { STW } \\
\text { Type }\end{array}$ & $\begin{array}{l}\text { Population } \\
\text { served }\end{array}$ & Grid reference & $\begin{array}{l}\text { Altitude } \\
\text { (m) }\end{array}$ & Date \\
\hline Alva & AS & 4673 & NS 874966 & 10 & $12 / 08 / 03$ \\
\hline Armadale & $\mathrm{PF}$ & 9770 & NS 937695 & 130 & $21 / 07 / 03$ \\
\hline Ashgill & AS & 1069 & NS 789503 & 100 & 20/08/03 \\
\hline Avonbridge & $\mathrm{PF}$ & 689 & NS 914728 & 140 & 04/08/03 \\
\hline Balfron & $\mathrm{PF}$ & 1412 & NS 548883 & 50 & $11 / 08 / 03$ \\
\hline Bathgate & $\mathrm{PF}$ & 10,150 & NS 961705 & 120 & 17/06/03 \\
\hline Bridgend & $\mathrm{PF}$ & 940 & NT 043759 & 80 & $14 / 07 / 03$ \\
\hline Buchlyvie & AS & 469 & NS 574942 & 30 & $31 / 07 / 03$ \\
\hline Callander & $\mathrm{PF}$ & 2381 & NN 636072 & 70 & 08/07/03 \\
\hline \multicolumn{6}{|l|}{ Carstairs } \\
\hline Junction & $\mathrm{PF}$ & 2752 & NS 962451 & 190 & 25/07/03 \\
\hline Coursington & AS & 6568 & NS 757578 & 60 & 21/08/03 \\
\hline Denny & AS & 10,677 & NS 821829 & 30 & $13 / 08 / 03$ \\
\hline Doune & $\mathrm{PF}$ & 1235 & NN 729008 & 10 & 11/06/03 \\
\hline Dunblane & AS & 7375 & NN 782005 & 70 & 12/06/03 \\
\hline Dunnswood & AS & 29,510 & NS 781772 & 60 & 16/07/03 \\
\hline Fallin & $\mathrm{PF}$ & 2447 & NS 836923 & 10 & 23/06/03 \\
\hline Fauldhouse & $\mathrm{PF}$ & 4874 & NS 942604 & 190 & 30/07/03 \\
\hline Fintry & AS & 462 & NS 614873 & 80 & 09/07/03 \\
\hline Gorebridge & $\mathrm{PF}$ & 4000 & NT 341613 & 110 & 15/07/03 \\
\hline Killearn & AS & 3200 & NS 516845 & 30 & 25/06/03 \\
\hline Linlithgow & $\mathrm{PF}$ & 12,200 & NS 986779 & 30 & 22/07/03 \\
\hline Maudslie & $\mathrm{PF}$ & 18,364 & NS 786503 & 40 & $14 / 08 / 03$ \\
\hline Peebles & $\mathrm{PF}$ & 7000 & NT 272398 & 160 & 11/07/03 \\
\hline Penicuik & AS & 13,500 & NT 246609 & 150 & 10/07/03 \\
\hline Plains & $\mathrm{PF}$ & 2376 & NS 797664 & 150 & 15/08/03 \\
\hline Plean & AS & 1518 & NS 842871 & 30 & 16/06/03 \\
\hline Stirling & AS & 42,202 & NS 808934 & 10 & 01/08/03 \\
\hline Strathblane & $\mathrm{PF}$ & 2019 & NS 547802 & 40 & 06/08/03 \\
\hline Westfield & $\mathrm{PF}$ & 570 & NS 939727 & 110 & 26/06/03 \\
\hline Winchburgh & $\mathrm{PF}$ & 2810 & NT 092744 & 80 & 24/06/03 \\
\hline
\end{tabular}


Table 2

\begin{tabular}{lll}
\hline Bat pass classification & Number & $\begin{array}{l}\text { \% of all } \\
\text { bat passes }\end{array}$ \\
\hline $\begin{array}{l}\text { Pipistrellus spp. } \\
\text { Myotis spp. }\end{array}$ & 3926 & 69.6 \\
Unknown bat spp. & 1380 & 6.0 \\
\hline P. pygmaeus & 2609 & 46.2 \\
P. pipistrellus & 135 & 2.4 \\
P. nathusii & 5 & 0.1 \\
Unknown Pipistrellus spp. & 1177 & 20.9 \\
\hline Social call & 1015 & \\
Feeding buzz & 422 & \\
All bat passes & 5644 & 100 \\
\hline
\end{tabular}


Table 3

\begin{tabular}{|c|c|c|c|c|c|c|}
\hline Source & $\mathrm{df}$ & $\begin{array}{l}\text { Adjusted } \\
\text { Mean Square }\end{array}$ & $\begin{array}{l}\text { Parameter } \\
\text { coefficient }\end{array}$ & $\begin{array}{l}\text { Coefficient } \\
\text { SE }\end{array}$ & $F$ & $p$ \\
\hline STW type & 1 & 1.379 & -0.3757 & 0.3618 & 1.08 & 0.310 \\
\hline Temperature & 1 & 17.89 & 0.3739 & 0.1000 & 13.99 & 0.001 \\
\hline Date & 1 & 9.396 & -0.0285 & 0.0105 & 7.35 & 0.012 \\
\hline Wind & 1 & 7.431 & -0.4171 & 0.1730 & 5.81 & 0.024 \\
\hline \% Built & 1 & 8.207 & 0.0607 & 0.0240 & 6.42 & 0.019 \\
\hline STW type* wind & 1 & 25.579 & 0.7841 & 0.1753 & 20.00 & 0.000 \\
\hline Error & 23 & 1.279 & & & & \\
\hline
\end{tabular}


Fig. 1

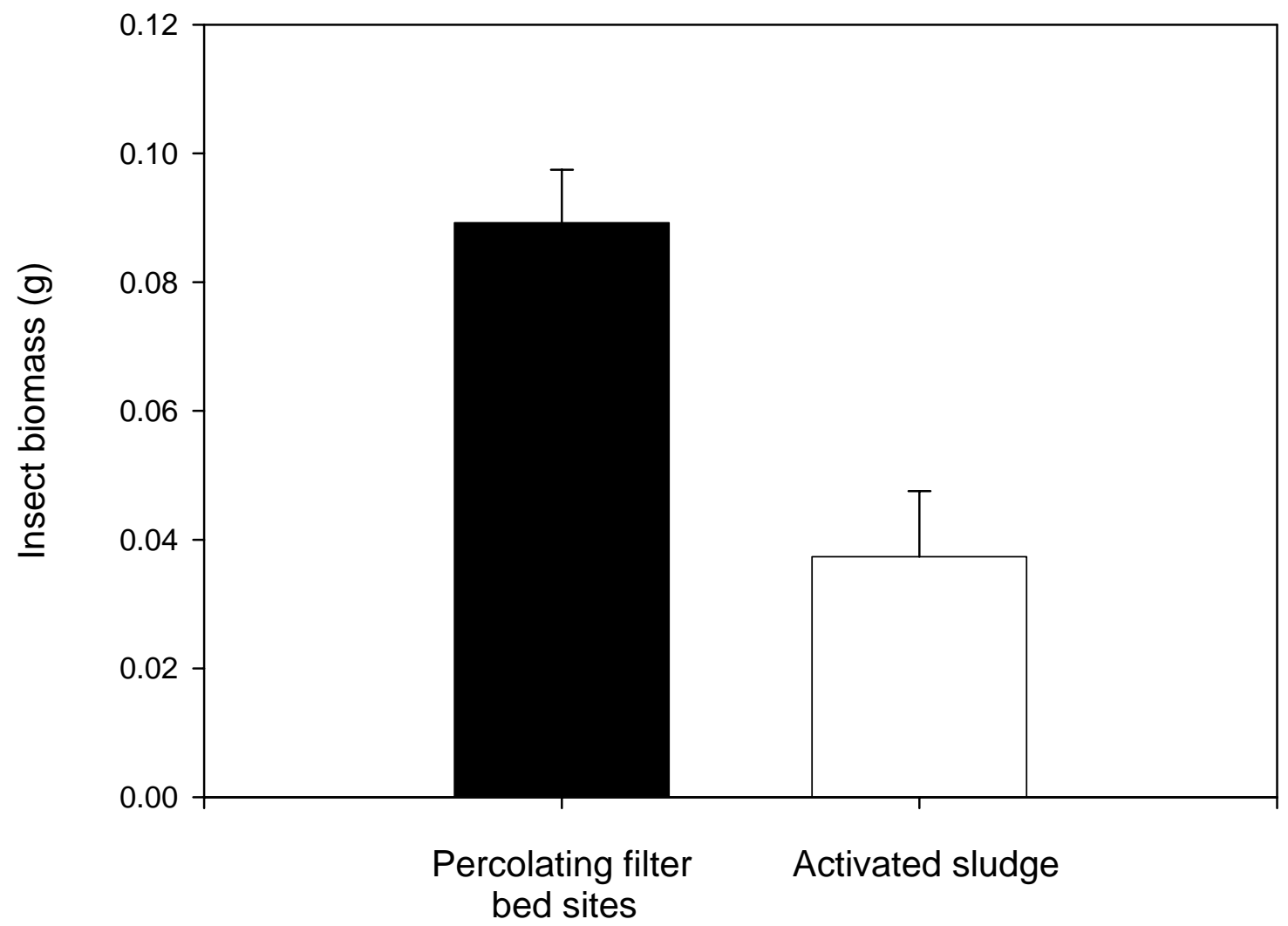


Fig. 2

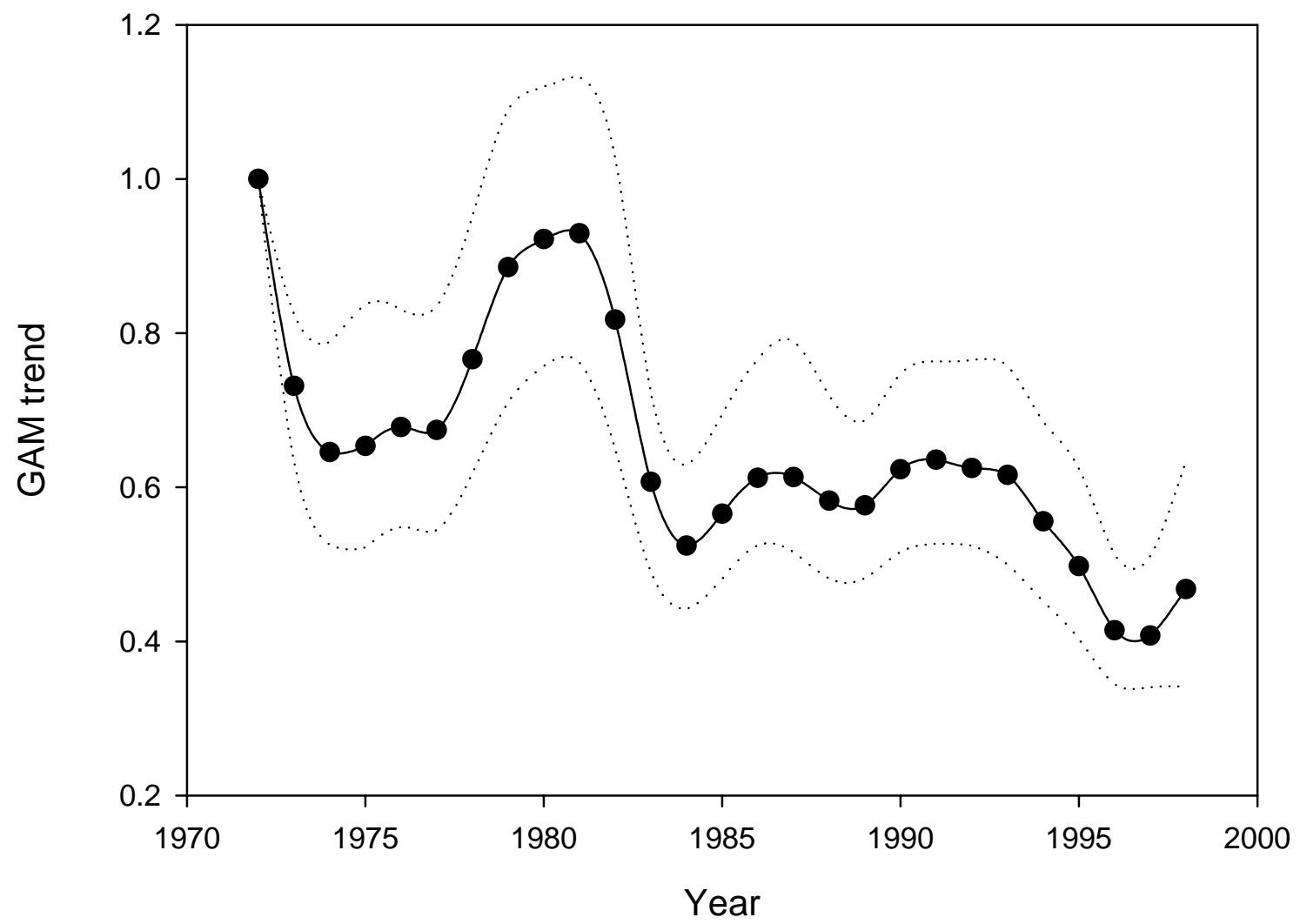


Fig. 3

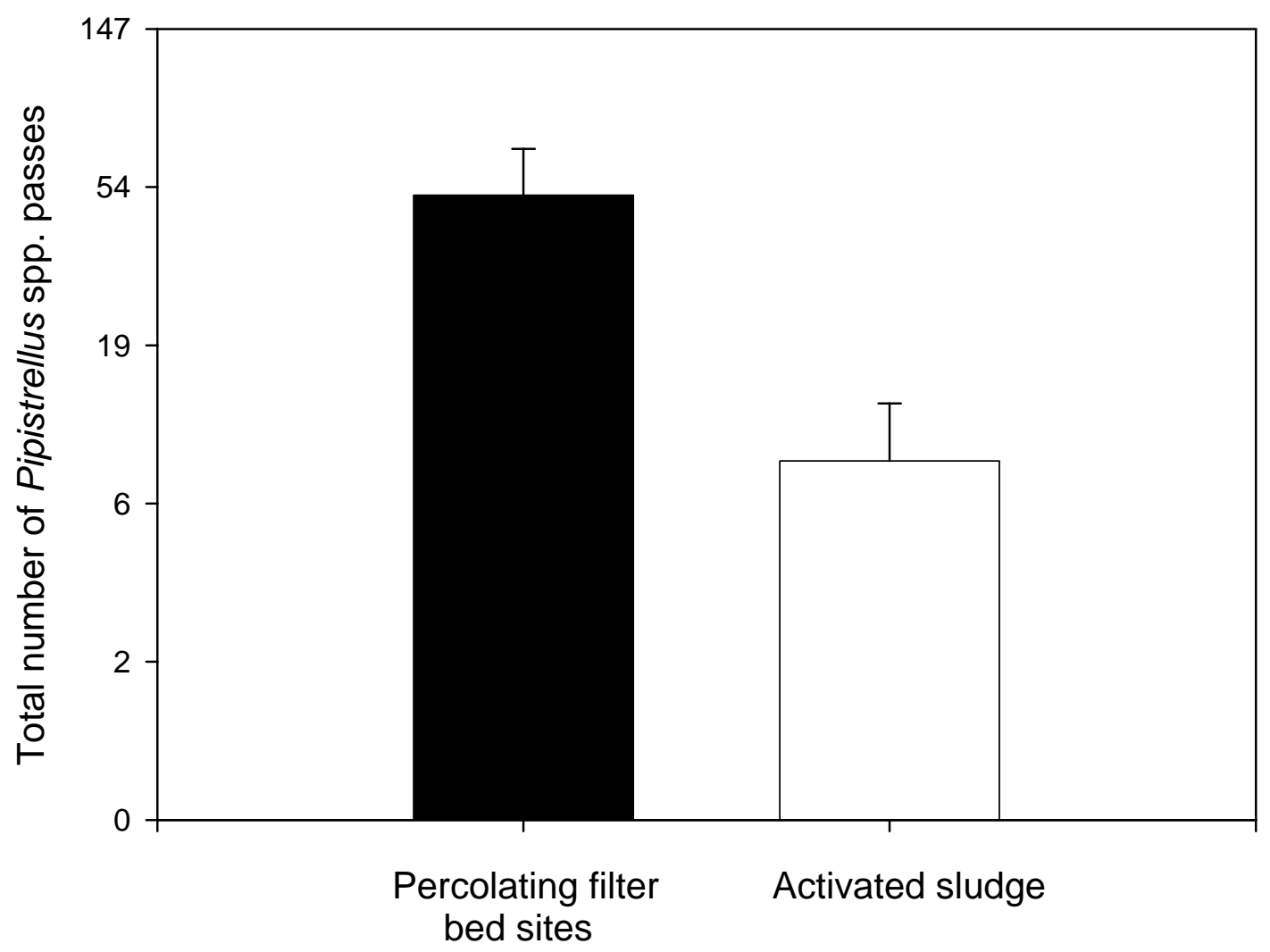


Fig. 4

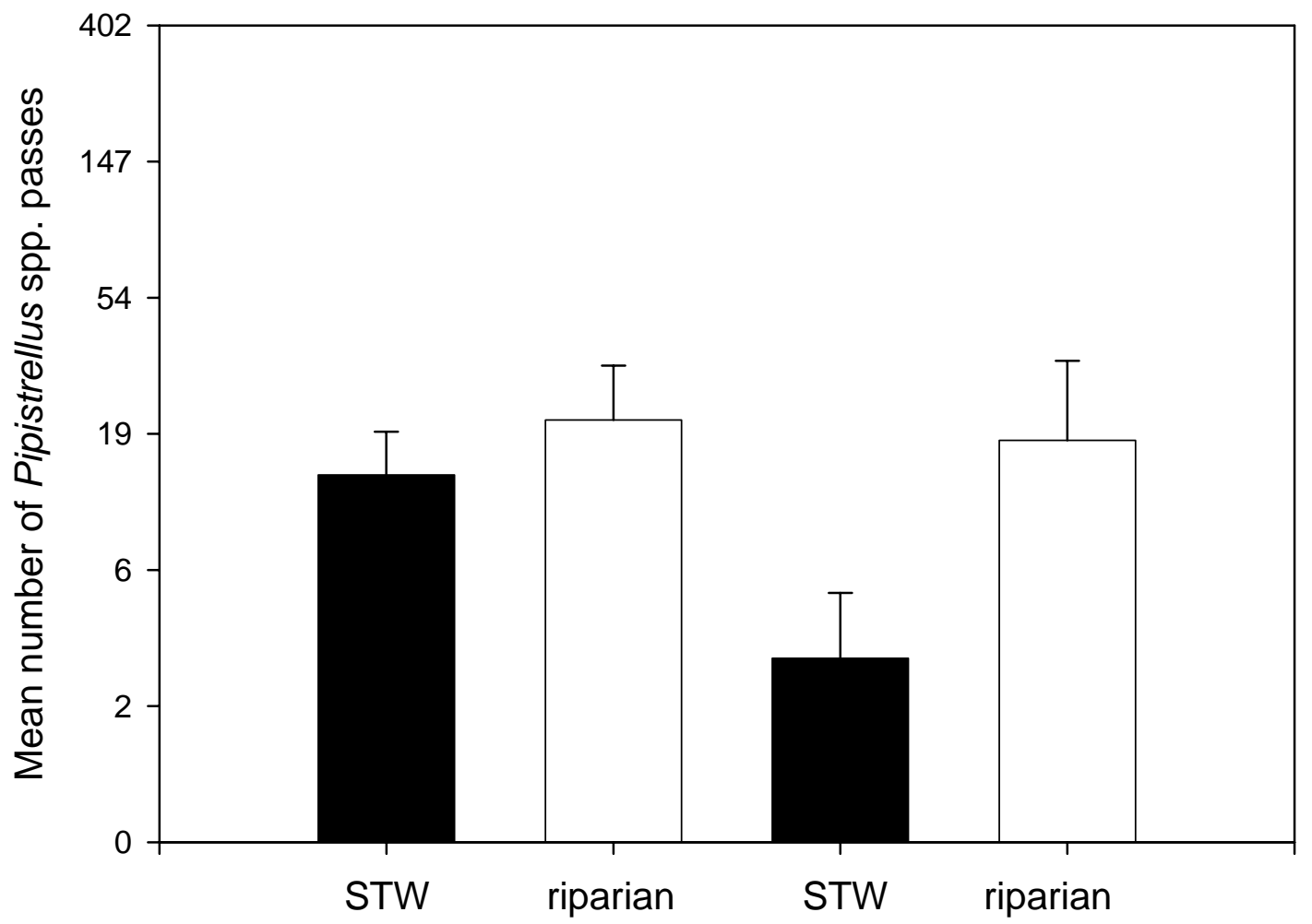

Percolating filter bed sites Activated sludge sites 